taken by biotechnology companies in such a way as to ensure that gains are taxed as capital gains, not as income. European governments should also take to heart OTA's argument that the ease with which new companies can spring into existence in the United States, confusing though it may be for the stock markets, is a powerful spur to copious innovation and, perhaps more important, its rapid exploitation. It is, however, important to acknowledge that in the past two years, in Britain and West Germany, venture capitalism has been growing even faster than biotechnology. Whether the same governments will sanctify this trend with tax advantages comparable with those enjoyed in the United States remains to be seen.

By themselves, however, these differences do not explain why Japan should be distinguished from Western Europe as the ground in which biotechnology is more likely to flourish. Indeed, Japan (like West Germany until very recently) differs radically from the United States in that venture capital plays only a minor part in the capital financing of industry. OTA's argument is that several Japanese companies have admirable expertise in the exploitation of fermentation technology (which is true), that Japan is a huge market for pharmaceuticals (which is likely to be important in the short run) and that the Ministry of International Trade and Industry in Tokyo has launched a cooperative programme in biotechnology (which is less significant than OTA appears to think). Readers of the report will, however, conclude that OTA is most of all impressed at the number of Japanese companies that have declared their determination to prosper in biotechnology and which are likely to turn their ambitions into reality with the zeal that has marked the success of Japanese manufacturers of automobiles and of electronic consumer goods. That is an awesome prospect but not a proof that European companies will be also-rans.

For those who would predict the future, one missing element in these calculations is the character of the relationship between the newer biotechnology companies and the larger companies with ambitions in the same field. OTA is probably right to guess that partnerships between big and small companies that already exist will often develop into even stronger relationships, outright mergers included. For large companies, which may have been slow to respond to the opportunities presented by biotechnology in the past decade, often enjoy the luxury of being able to bide their time, relying on their financial resources to be able to move quickly when the time is ripe. And once committed to the development of a new product, established companies have an advantage that newly established companies cannot but envy - an established and sometimes efficient mechanism for putting what they seek to sell into the hands of customers. Especially now that it has become plain that the benefits of biotechnology are further away than at first seemed possible, the large pharmaceutical and chemical manufacturers now operating on an international basis have powerful advantages over most newly created companies. None of this implies that there is no place for the smaller companies, nor even than none of them will grow big; indeed, OTA is entirely right to emphasize the value of the smaller companies as spurs to innovation in the past few years. But the growing importance of the multinational manufacturers in the development of biotechnology is yet another reason why pure chauvinism is out of place.

In the circumstances, the positive recommendations put forward by OTA are probably less urgent than they seem. OTA would have the administration reverse the recent decline of support for basic biological research (for which there are other good reasons) and do something unspecified to strengthen "bioprocess engineering" (for which there are few precedents). In strictly parochial terms, indeed, the threat that if Congress should fail to provide extra resources in those fields, the United States may lose its "commanding lead" to Japan or some other nation may be effective. It will be interesting to see how that issue is decided. Meanwhile, the chief value of OTA's gigantic study is that it has provided a unique snapshot of a new and important industry at a critical epoch in its growth, no longer neonate, still far short of puberty.

\section{Binary is divisive}

\section{Britain's system of higher education suffers from too little diversity and from being split in two.}

FOR how much longer can the British system of higher education be allowed to continue as if it were two separate systems, one consisting of institutions called universities financed by central government through the University Grants Committee and the other consisting of institutions called polytechnics whose bills are paid by local authorities (with money provided by the central government)? The question has been in the air ever since the polytechnics were designated as degree-giving establishments nearly twenty years ago. The argument then was that there would be virtues in operating a dual system of higher education, if only because the newly established polytechnics could be guided, or coerced, to take a direct interest in the vocational needs of their students. It was almost as if the late Mr Anthony Crosland, the then Secretary of State for Education and himself once a university teacher, egged on by his Oxbridge civil servants, had washed his hands of the universities and decided that a quite different system would better serve the social need of higher education. In the event, the binary system (Mr Crosland's name for it) has not been much of a success. While many polytechnics have stuck admirably to their brief, and have won respect for their teaching and research in the process, others (there are twenty-six altogether) have aped the universities in the breadth of the curricula on offer, or have embraced unproved and therefore mischievous courses (admittedly fashionable in the 1960s) with elaborate titles such as "independent study", or have merely become dull. And sadly, both among academics and would-be students, the polytechnics are less eagerly sought after than are the universities.

Now, though, there is a chance that this may be changed. Guilefully, the Department of Education and Science has persuaded the universities that the system they operate for administering applications to enter universities from school students should also be used to administer applications for entry to the polytechnics. The scheme (whose cost will be met by the government) will operate for a trial period of two years, but everybody concerned insists that students wishing to hedge their bets on securing a place somewhere in higher education will have to complete two separate application forms, the data on which will be sedulously kept separate. This is either a nonsense or the thin end of a wedge, one that leads to a unified procedure for entry into higher education of either kind.

And not before time. Not merely young people looking for places in higher education but those who eventually employ them are thoroughly confused by the present system, which is a disgraceful monument to the corrosiveness of academic snobbery. Both types of institutions allow young and not-soyoung people to earn degrees, whose authenticity in the case of the polytechnics is vouched for by an independent council. Polytechnics, it is true, lack people called vice-chancellors, and have directors instead. Senior teachers are called "heads of department", not professors. And they have courses in hotel management and catering as well as in Latin and Greek. But could all British universities justly claim that they are themselves so very different?

If not, university academics should follow the only honourable course open to them, and clamour for the abolition of the binary system by means of the abolition of the boundary between its two unjustly unequal parts. The opportunity will arise when they come to reply to the questionnaire put out last autumn by the stillnew chairman of the University Grants Committee, enquiring in a neutral fashion about university opinion on the binary system. The practical benefits are obvious - students will no longer be quite as mystified, while more efficient use will be made of scarce resources. More important, however, the British system of higher education would at one swoop acquire the diversity of institutions only now being forced to emerge by financial deprivation. 